\title{
Impact of sustained weight loss achieved through gastric gastric sleeve surgery with circulating level of obestatin hormone in Iraqi obese subjects.
}

\author{
Lect. Dr. Zainab A. Razak A. GhaniMBchB, MsC.* Lec. \\ Dr. Ramiz Sami MukhtarMBchB, FRCS.** \\ **Lec. Dr. MuayadAbassFadhelMBchB, FACS, FICMBS., \\ Prof. Dr. Kisma M. Turki. PhD.* \\ *Department of biochemistry, **Department of surgery, university of Baghdad, collage of medicine.
}

\begin{abstract}
:
Background: The epidemic of obesity is a major health problem in the developed world with a great influence on morbidity and mortality. Diet therapy, with and without support organizations, is relatively ineffective in treating obesity in the long term. Laparoscopic sleeve gastrectomy (LSG) has been introduced as a surgical option. Obestatin has been reported to have actions opposite to ghrelin, such as decreasing food intake, body weight, and delaying gastric emptying, and to antagonize the actions of ghrelin when both peptides are co administered.

Aim of study: To evaluate serum obestatin levels achieved through sleeve gastrectomy and on insulin resistance and the serial changes of insulin concentration in obese patients and to determine the effect of weight loss after sleeve gastrectomy on free testosterone and sex hormone binding globulin levels and sexual quality of life in obese men and women.

Subjects and methods: Twenty four patients undergone gastric sleeve surgery with 25 controls were selected. Body mass index, waist circumference (WC), lipid profile, fasting blood sugar, glycated hemoglobin (HbAlc), fasting insulin, QUICKI, free testosterone, sex hormone binding globulin and ghrelin hormone concentration were measured for patients prior gastric sleeve and for controls, another measures done one month and then three months post-surgery.

Results:a significant decline were noticed in BMI, WC, TC, TG, LDL-cholesterol, fasting insulin, and ghrelin, with significant increase in QUICKI and SHBG in patient undergone gastric sleeve surgery with a significant differences in all studied parameters between patients and controls except free testosterone and SHBG. A significant negative correlation was shown between obestatin and BMI and between obestatin and fasting insulin in patients before sleeve gastrectomy.

Conclusion: Bariatric surgery represents a promising treatment option in morbidly obese patients and low level of obestatinsuggested that this hormone is a nutritional marker reflecting body adiposity and insulin resistance.

Key word: obesity, bariatric surgery, obestatin.
\end{abstract}

\section{Introduction}

The epidemic of obesity is a major health problem in the developed world with a great influence on morbidity and mortality. Dietary and behavioral approaches to obesity have met with limited success and bariatric surgery is currently the only effective therapy for morbid obesity. Benefits of surgery include durable weight loss, improved cardiovascular profile, remission of type II diabetes, and better quality of life.(1)

Apart from the psychobiological factors, there is also a 'brain phase' in the food intake process. Experimental data have indicated the presence of several peptides with their receptors in the hypothalamus and other parts of the central nervous system that may affect the quantity and quality of food intake. These peptides act as sensors that transfer signals from the periphery and stimulate or inhibit appetite and food intake accordingly in order to maintain energy homeostasis; not only they regulate the amount of each meal but also long-term energy reserves (i.e. the amount of fat tissue).(2)

Unfortunately, diet therapy, with and without support organizations, is relatively ineffective in treating obesity in the long term. There are currently no truly effective pharmaceutical agents to treat obesity, especially morbid obesity. In 1991, the National Institutes of Health established guidelines for the surgical therapy of morbid obesity (BMI $\geq 40$ or $\mathrm{BMI} \geq 35$ in the presence of significant comorbidities), now referred to as bariatric surgery.(3)

Sleeve gastrectomy (SG): in which the stomach is transected vertically over a 34 or $36 \mathrm{~F}$ bougie creating a gastric tube and leaving a pouch of 100 to $200 \mathrm{~mL}$. Although many regard SG as a restrictive 
procedure, it is increasingly recognized as a metabolic procedure.(4)Laparoscopic sleeve gastrectomy (LSG) has been introduced as a surgical option. It involves removing approximately 80 percent of the stomach, mainly the body and fundus, leaving behind only a gastric tube along the lesser curve. This gastric tube has been shown to have less distensibility than the whole stomach, with high intraluminal pressure, thus restricting the amount of food that can be consumed at one time. (5)

Obestatin, a 23-amino acid peptide derived from the ghrelin peptide precursor (preproghrelin), derived from the C-terminal portion of the 117 amino acid preproghrelin precursor identified using bioinformatic analyses of the preproghrelin genomic sequence in different species, was identified in 2005 as a physiological opponent of ghrelin. (6)

Obestatin has been reported to have actions opposite to ghrelin, such as decreasing food intake, body weight, and delaying gastric emptying, and to antagonize the actions of ghrelin when both peptides are co administered. However, obestatin did not alter GH secretion, and circulating obestatin levels were not increased after fasting .Moreover, it has been suggested that obestatin readily crosses the blood-brain barrier but is rapidly degraded, all available data have suggested that obestatin is a relevant player in energy balance regulation, which could open up the possibility of targeting the GRP-39 receptor for the development of antiobesity drugs.(7)

A number of studies have failed to confirm the anorexigenic effect of obestatin and its agonist properties on GPR39 Therefore, to date, some biological actions of obestatin seem to be controversial and its specific receptor remains unknown. Many data suggest a relevant role of peptides encoded by the ghrelin gene in glucose balance and their implications for diabetes.(8)

Epidemiological observations suggest that low plasma levels of SHBG and free testosterone are associated with increased risk for type 2 diabetes. Furthermore, the plasma concentrations of these hormones have been reported to be lower in men with type 2 diabetes than in non-diabetic subjects.(9)

Although the mechanisms underlying the association between plasma levels of sex steroid hormones and type 2 diabetes are not entirely understood, it has been postulated that low plasma levels of both SHBG and bioavailable testosterone contribute to the development of insulin resistance and, through this effect, to the complex metabolic abnormalities that lead to type 2 diabetes in men. However, low plasma levels of free testosterone are also observed in obesity, particularly in abdominal/ truncal obesity, a condition that is itself independently accompanied by insulin resistance and heightened risk for type 2 diabetes. (10)

The aims of this studyto evaluate serum obestatin levels achieved through sleeve gastrectomy and on insulin resistance and the serial changes of insulin concentration in obese patients and to determine the effect of weight loss after sleeve gastrectomy on free testosterone and sex hormone binding globulin levels and sexual quality of life in obese men and women.

Subjects and methods:

This study was conducted during the period from December 2012 until the end of June 2013. Thirty three (33) patients with morbid obesity who undergone gastric sleeve surgery were selected from department of surgery in Baghdad teaching hospital and from Saint Raphael private hospital.

Twenty four (24) patients only ( eleven male and thirteen female ) followed the schedule of this prospective study who subjected to three successive examination and blood sampling, the first examination was pre-operatively followed by two examination and blood sampling one month and then three months postsurgical operation.

In addition twenty five (25) healthy subjects with normal body mass index (ten males and fifteen females) were included in this study considered as control group.

All patients and controls underwent a full physical examination and completed a general questionnaire. Patients with suspected thyroid function disease, or hormonal abnormalities were excluded from the study.

Body mass index is calculated by dividing subjects weight in $\mathrm{Kg}$ by their height in $\mathrm{m} 2$. BMI calculated as:

$\mathrm{BMI}=$ weight $(\mathrm{kg}) /$ height $(\mathrm{m}) 2$

All patients and controls were weighted on the same scale, barefoot. Height was measured using the same measuring tape. (11)

Biochemical tests were measured for each patient before gastric sleeve followed by another measures one month and then three months after surgery. The same measurements were done for controls.

Fasting blood sugar, glycated hemoglobin, lipid profile were measured used an enzymatic methods.

Insulin hormone measured using ELIZA kit from RAYBIO (Enzyme-Linked Immunosorbent Assay) while assessment of insulin sensitivity calculated using the quantitative insulin sensitivity check index (QUICKI) QUICKI = $1 / \log$ (fasting serum insulin) + log (fasting glucose) where fasting serum insulin is micro units per milliliter (mU/ML) and fasting serum glucose is in microgram per deciliter $(\mathrm{mg} / \mathrm{dl})$ in the equation. (12) 
Free testosterone and SHBG were determined using kits from Alpha Diagnostic International ELISA test is intended for in vitro research use only.

Serum obestatin level was determined using RayBio® Obestatin Enzyme Immunoassay (EIA) Kit is an in vitro quantitative assay for detecting Obestatin peptide based on the principle of Competitive Enzyme Immunoassay.

\section{Statistical Analysis}

Statistical analysis was carried out using SPSS SPSS-16 (Statistical Package for Social Science version 16)"PASW Statistics. Data is reported as mean \pm standard error, and statistical significance was assumed at $\mathrm{P}<0.05$, unless otherwise stated. Differences in the fasting plasma levels of obestatin were assessed by paired t- test.

\section{Results:}

Table (1) demonstrated the significant differences in all studied parameters between patient prior gastric sleeve surgery and control groups, with $\mathrm{p}$ value equal to 0.001 for body weight, BMI, waist circumference, fat $\%$, total cholesterol, triglyceride, and insulin. In addition a significant differences were noticed in LDL- cholesterol $(p=0.008)$, HDL-cholesterol $(p=0.004)$, FBS $(p=0.008)$, HbA1c $(p=0.007)$ and QUICKI $(\mathrm{P}=0.05)$

\begin{tabular}{|c|c|c|c|}
\hline Studied parameters & Patients $(n=24)$ & Controls $(n=25)$ & P value \\
\hline Body weight (kg) & $131.8 \pm 6.7$ & $62.53 \pm 2.5$ & $0.001(S)$ \\
\hline BMI ( kg/m2) & $48.02 \pm 1.8$ & $22.19 \pm 0.71$ & $0.001(\mathrm{~S})$ \\
\hline waist circumference (cm) & $101.63 \pm 1.6$ & $83.20 \pm 2.2$ & (20.001(S) \\
\hline $\begin{array}{ll}\% & \text { Fat percent }\end{array}$ & "49.7 \pm 2.1 & $17.67 \pm 0.99$ & $0.001(\mathrm{~S})$ \\
\hline cholesterol (mg/dl) & $200.51 \pm 5.04$ & $172.0 \pm 3.5$ & $0.001(\mathrm{~S})$ \\
\hline $\begin{array}{l}T G \\
) m g / d l(\end{array}$ & $154.81 \pm 1.95$ & $121.6 \pm 4.3$ & $0.001(S)$ \\
\hline LDL-chol (mg/dl) & $114.38 \pm 3.39$ & $102.48 \pm 2.6$ & $0.008(S)$ \\
\hline HDL-chol (mg/dl) & $54.03 \pm 1.64$ & $60.49 \pm 1.3$ & $0.004(\mathrm{~S})$ \\
\hline F.B.S. $(\mathrm{mg} / \mathrm{dl})$ & $103.79 \pm 4.01$ & $90.81 \pm 2.2$ & $0.008(S)$ \\
\hline HbA1c \% & $6.400 \pm 0.272$ & $5.531 \pm 0.13$ & $0.007(\mathrm{~S})$ \\
\hline Fasting insulin MIU/ml & $23.183 \pm 0.804$ & $6.346 \pm 0.23$ & $0.001(\mathrm{~S})$ \\
\hline QUICKI & $2.7469 \pm 0.0166$ & $3.2150 \pm 0.026$ & $0.05(\mathrm{~S})$ \\
\hline free testosterone $\mathrm{pg} / \mathrm{ml}$ & $47.11 \pm 8.53$ & $61.6 \pm 19$ & $0.501(\mathrm{NS})$ \\
\hline nmol/L)SHBG ( & $57.39 \pm 4.01$ & $\begin{array}{lll}76.1 & \pm 5.4 \\
\end{array}$ & (0.01(NS) \\
\hline
\end{tabular}

S: significant, NS: non-significant.

Table (2) showed a significant differences in each of body weight $(\mathrm{p}=001)$, BMI $(\mathrm{p}=0.07)$, waist circumference $(\mathrm{p}=0.05)$, fat $\%(\mathrm{p}=0.001)$, TG $(\mathrm{P}=0.05)$, fasting insulin $(\mathrm{p}=0.09)$, QUICKI $(\mathrm{p}=0.05)$, and SHBG $(\mathrm{P}=0.05)$ in patients before gastric sleeve and one month post surgery, while there were a significant differences in body weight $(\mathrm{p}=0.001)$, BMI $(\mathrm{P}=0.001)$, waist circumference $(\mathrm{p}=0.001)$, fat $\%(0.001)$, total cholesterol $(\mathrm{p}=0.05)$ TG $(\mathrm{P}=0.001)$, LDL- cholesterol $(\mathrm{p}=0.06)$, HbA1c $(\mathrm{p}=0.07)$, fasting insulin $(\mathrm{p}=0.001)$, QUICKI $(\mathrm{p}=0.06)$, and SHBG $(\mathrm{P}=0.07)$ in patients before gastric sleeve and three months post surgery.

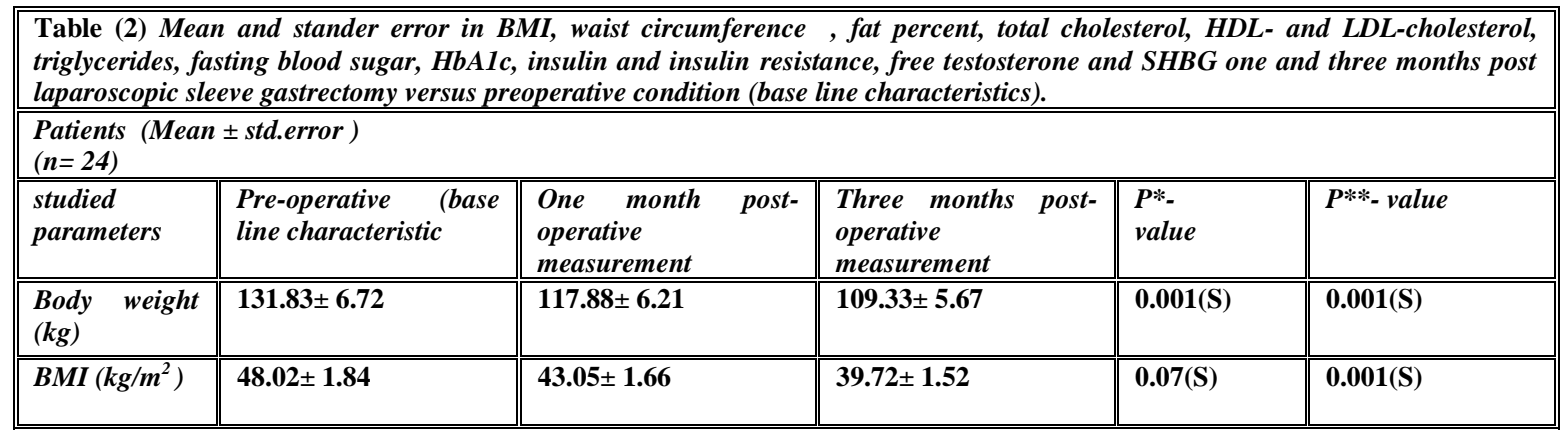



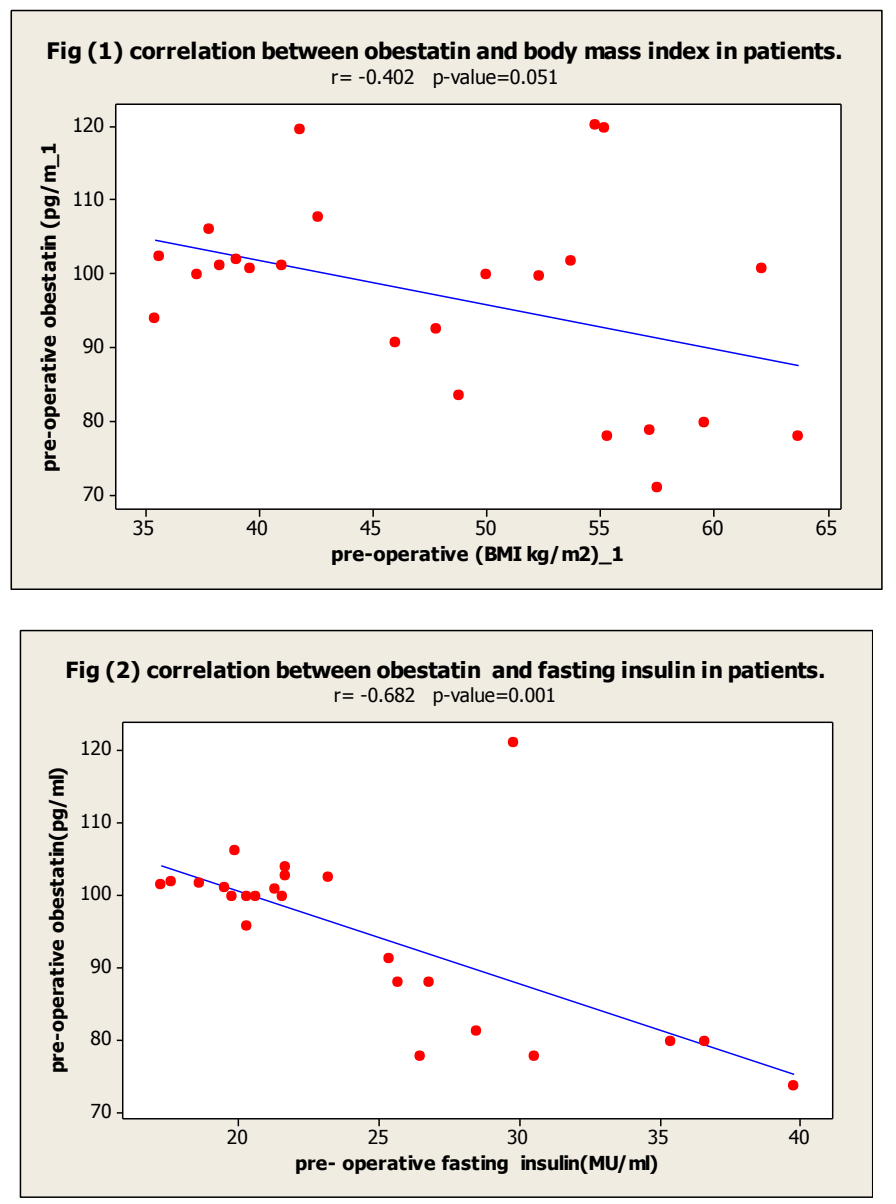

IV. Discussion:

Most publications have looked at bariatric procedures from one particular point of view. This study tried to take into consideration a lot of metabolic effects. It is valuable to observe changes not only in one parameter, but also in the correlations of parameter groups. Therefore, this study presents not only changes in gastric hormones (ghrelin and obestatin) but also in insulin, glucose and parameters of metabolic syndrome, in order to determine the better results of gastric sleeve in reducing the effects of obesity.

The present study showed a significant decline in body mass index, waist circumference, and fat percent among patients undergone gastric sleeve surgery with a significant differences between patient and controls which is agreed by Gautier $\mathrm{T}$ et al. (13)indicated that weight loss was significantly improved after bariatric surgery (mean loss percentage of excess of body weight, $64.6 \%$ versus $47.1 \%$ ) and all reflux symptoms are eliminated without any medication at the end of the follow-up.

Several studies have demonstrated that the amelioration of metabolic dysfunction is attributable not only to weight loss and caloric restriction, but also to endocrine changes resulting from surgical manipulation of the gut. (14)

Bariatric surgery results in an improvement in hyperlipidemia. In a systematic review and metaanalysis, hyperlipidemia improved in over $70 \%$ of operated patients. In particular, total cholesterol, lowdensity lipoprotein and triglycerides decreased by an average of $0.86 \mathrm{mmol} / \mathrm{L}, 0.76 \mathrm{mmol} / \mathrm{L}$ and $0.90 \mathrm{mmol} / \mathrm{L}$ respectively, while high-density lipoprotein showed no significant change.(3)

The benefits of bariatric surgery extend beyond amelioration of hyperglycemia, and include improved lipid profile and blood pressure control. A meta-analysis of 236 studies and 22094 patients showed marked decrease in total cholesterol, low-density lipoprotein cholesterol and triglycerides after bariatric procedures.(3) Silecchia G and co-workers.(15) Contribute to a noticeable improvement of the other components of metabolic syndrome, such as triglycerides, cholesterol and its fractions after bariatric surgery.

Improvement in glucose homeostasis is an expected outcome of weight loss in obese individuals due to either medical or surgical intervention. Insulin sensitivity increases markedly after bariatric surgery, accompanied by elevated adiponectin levels, enhanced markers of insulin signaling in key target tissues, favorable changes in enzymes mediating glucose and fatty acid metabolism, and decreased intramuscular and intrahepatic lipids. (14) 
Many reports have identified improvement in glucose homeostasis after bariatric surgery that is independent of weight loss. Bariatric procedures causing loss of body weight improve glucose metabolism and reduce insulin resistance, which explains the results in remission of T2DM. In regard to the unquestionable impact of bariatric procedures on the T2DM, in which hyperinsulinemia is closely associated with insulin resistance.(16)

Hady H R et al.(17) found significant differences in insulin and glucose concentrations among patients after LSG. With a statistically significant reduction in insulin. Insulin resistance expressed by HOMA IR among patients showed more noticeable reduction seven days and one month after the surgery in the LSG but the most significant decrease occurred seven days and three months after the surgery.

Obesity affects all 3 levels of the hypothalamic pituitary gonadal axis, and nonsurgical weight loss, as well as bariatric surgery, have been shown to improve function at all 3 levels. The improvement in hypogonadism ultimately occurs due to an increase in testosterone. An increase in SHBG and decreased estradiol has also been postulated as an improvement. The decrease in fat mass associated with weight loss might also decrease the fat deposition in the abdomen, thighs, and scrotum, thus decreasing the testicular temperature and facilitating spermatogenesis.

There are a few published reports evaluating the effect of sustained weight loss on sexual hormones in male morbidly obese patients [defined by body mass index (BMI) higher than $40 \mathrm{~kg} / \mathrm{m} 2$ ]. Most of them have found that obese males show decreased sexual quality of life, reduced fertility, and hormonal changes including decreased testosterone levels (both free and total), increased estradiol in comparison to the general population as well as a decrease of the sex hormone binding globulin (SHBG) .The changes of gonadotropin serum levels observed in obesity are more controversial but inappropriate normal levels .suggesting a hypogonadotropichypogonadism situation is generally found.(18)

Mulligan et al(19) found that hypogonadal patients had a higher BMI (mean BMI, $31.5 \mathrm{~kg} / \mathrm{m} 2$ ) compared with eugonadal patients (mean BMI, $28.5 \mathrm{~kg} / \mathrm{m} 2$ ).

It has been suggested that obesity-associated male hypogonadism is related to the central inhibition of gonadotropin secretion, but the mechanisms are yet unknown. One hypothesis that hypothalamic $\mathrm{GnRH}$ secretion may be inhibited by the increased estradiol from excessive peripheral conversion of testosterone in the adipose tissue. However, not all studies have shown a decrease in estradiol levels after weight loss . On the other hand, inhibin B and anti-Müllerian hormone (AMH), which reflect Sertoli cell function, have been less explored in male obesity.(20)

It is generally believed that high insulin levels found in insulin-resistant females stimulate the ovary to secrete androgens either through binding to the insulin receptor or to the insulin-like growth factor-1 receptor through phenomenon known as specificity spillover. Insulin sensitivity generally improves when the hyperandrogenism is corrected.(21)

The present study also showed a significant increase in serum level of SHBG which is agree with Pellitero S and coworkers. (20) Who demonstrated thatafter bariatric surgery, a significant increase of SHBG levels is observed, which has been attributed to the dramatic fall in insulin and leptin serum levels due to the weight loss effect.

Another two studies reported a statistically significant increase of SHBG levels after bariatric surgery. (22) and (23)but this disagreed with the study of Omanaet al. (24) who reported that the increase in SHBG levels after bariatric surgery, although trending strongly, was not significant.

obestatin was suggested to contribute to appetite and body weight regulation by antagonizing the effects of ghrelin. Although several studies failed to reproduce the anorexigenic actions of obestatin, this peptide, when co-administered with ghrelin, was revealed to be an interesting pharmacological tool with respect to blocking some of the effects of ghrelin. (25)

This study showed a significant increase in serum obestatin in patient underwent gastric sleeve at one and three months post operation with a significant difference in serum obestatin between patients and controls. This agreed with Chen CY et al study. (26) which found that plasma obestatin concentrations significantly increased in patients after SG $(\mathrm{P}<0.05)$.

Other reports supported this study, Haideret al.(27)MeasuredObestatin levels in a group of morbidly obese subjects and compared with a group of lean patients. Obestatin levels have been demonstrated to be lower in obese subjects when compared with lean subjects, showing a significant increase in the obese patients after bariatric surgery. These findings seem to support the concept that disparate post-translational cleavage of preproghrelin into these two sibling peptides may be regulated differently in the presence of obesity or, alternatively, that the common regulatory factors are responsible for these still poorly defined coordinate changes of the ghrelin and obestatin system according to the nutritional status.

In this study a significant negative correlation was noticed between obestatin and body mass index in patients underwent gastric sleeve which is agreed with a study of Nakahara T et al. (28) Who detected that obestatin was negatively correlated wth body mass index (BMI) $(r=-.74)$, glucose $(r=-0.56)$, insulin $(r=-0.55)$. 
In Lippl $\mathrm{F}$ et al study. (29)Demonstrated that Obestatin levels correlated inversely and significantly with body mass index (f: $\mathrm{r}=-0.632, \mathrm{p}<0.001 ; \mathrm{m}$ : $\mathrm{r}=-0.487, \mathrm{p}<0.001$ ) and basal insulin levels (f: $\mathrm{r}=-0.536, \mathrm{p}<0.001$; $\mathrm{m}$ : $\mathrm{r}=-0.320, \mathrm{p}=0.008)$ in females and males.

In Kang JG et al. (30) study found that fasting serum obestatin levels were negatively correlated with BMI, waist circumference, fasting insulin levels, fasting c-peptide levels and HOMA-IR.

\section{Conclusion:}

Bariatric surgery represents a promising treatment option in morbidly obese patients, leading to reduced CVD morbidity and mortality; several co-morbidities such as hypertension, dyslipidemia, diabetes are also improved,(31) in addition a low level of obestatin demonstrated in obesity suggested that obestatin is a nutritional marker reflecting body adiposity and insulin resistance.

\section{References:}

[1]. Colquitt J, Clegg A, Sidhu M, et al. Surgery for morbid obesity. Cochrane Database Syst Rev 2003;CD003641

[2]. Dallma MF. Stress-induced obesity and the emotional nervous system.Trends EndocrinolMetab.2009; 21:159-65. [PMC free article] [PubMed

[3]. Buchwald H. A bariatric surgery algorithm. Obes Surg. 2002;12733-746.

[4]. Scott WR, Batterham RL: Roux-en-Y gastric bypass and laparoscopic sleeve gastrectomy: understanding weight loss and improvements in type 2 diabetes after bariatric surgery. Am J PhysiolRegulIntegr Comp Physiol. 2011; 301:R15-27.

[5]. TzioniYehoshua R, Eidelman AL, Stein M, et al Laparoscopic sleeve gastrectomy—volume and pressure assessment. Obes Surg. 2008;18:1083-1088

[6]. Zhang JV, Re PG, Avsian-Kretchmer O, Luo CW, Rauch R, et al. Obestatin, a peptide encoded by the ghrelin gene, opposes ghrelin's effects on food intake.2005; Science310: 996-999. [PubMed].

[7]. McKee KK, Tan CP, Palyha OC, Liu J, Feighner SD, Hreniuk DL, Smith RG, Howard AD, Van der PloegLH Cloning and characterization of two human G protein-coupled receptor genes (GPR38 and GPR39) related to the growth hormone secretagogue and neurotensin receptors. Genomics .1997; 46:426-434.

[8]. Ren AJ, Guo ZF, Wang YK, Lin L, Zheng X, Yuan WJ: Obestatin, obesity and diabetes. Peptides.2009, 30:439-444.PubMed Abstract | Publisher Full Text

[9]. Caldas AD, Porto AL, Motta LD, Casulari LA. Relationship between insulin and hypogonadism in men with metabolic syndrome. 2009; Nov;53(8):1005-11.

[10]. Lakshman KM, Bhasin S, Araujo AB. Sex hormone-binding globulin as an independent predictor of incident type 2 diabetes mellitus in men. Journals of Gerontology.Series A, Biological Sciences and Medical Sciences. 2010;65:503-509. doi:10.1093/gerona/glq002 [PMC free article] [PubMed].

[11]. Lopez-Jimenez F. and Miranda W.R.: Diagnosing obesity : beyond BMI., Virtual Mentor.2010; 12(4):292-298.

[12]. Kats A, Nambi SS, Mather K, Baron DA, Sullivan G, Quon MJ. ' Quantitative insulin sensitivity check index: a simple, accurate method for assessing insulin sensitivity in humans.J' . Clin.Endocrinol. Metab.2000;85:2402-2410.

[13]. Gautier T, Sarcher T, Contival N, Le Roux Y, Alves A. Indications and mid-term results of conversion from sleeve gastrectomy to Roux-en-Y gastric bypass. Obesity surgery. 2013;23(2):212-5.

[14]. Thaler JP, Cummings DE. Minireview: Hormonal and metabolic mechanisms of diabetes remission after gastrointestinal surgery. Endocrinology. 2009;150:2518-2525.

[15]. 15. Silecchia G, Boru C, PecchiaA et al. Effectiveness of laparoscopic sleeve gastrectomy (first stage of biliopancreatic diversion with duodenal switch) on comorbidities in super-obese high-risk patients. Obes Surg. 2006;16:1138-1144.

[16]. Spanakis E, Gragnoli C. Bariatric surgery, safety and type 2 diabetes. Obes Surg. 2009;19:363-368.

[17]. Hady H R, Golaszewski P, Zbucki R L, Dadan J ( 2012). The influence of laparoscopic adjustable gastric banding and laparoscopic sleeve gastrectomy on weight loss, plasma ghrelin, insulin, glucose and lipids.Folia Histochemica ET Cytobiologica.2012; Vol.50, pp. 292-303

[18]. Reis LO, Favaro WJ, Barreiro GC, et al. Erectile dysfunction and hormonal imbalance in morbidly obese male is reversed after OBES SURG gastric bypass surgery: a prospective randomized controlled trial. Int J Androl. 2010;33:736-44.

[19]. Mulligan T, Frick MF, Zuraw QC, et al. Prevalence of hypogonadism in males aged at least 45 years: the HIM study. Int J ClinPract. 2006;60:762-769.

[20]. Pellitero S, Olaizola I, Alastrue A \& Granada M ;HypogonadotropicHypogonadism in Morbidly Obese Males Is Reversed After Bariatric Surgery.2012; OBES SURG DOI 10.1007/s11695-012-0734-9.

[21]. Borissova, A.M., Tankova, T., Kamenova, P., Dakovska, L., Kovacheva, R., Kirilov, G., Genov, N., Milcheva, B. \&Koev, D. Effect of hormone replacement therapy on insulin secretion and insulin sensitivity postmenopausal diabetic women. Gynecological Endocrinology. 2002; 16, 67-74.

[22]. Hammoud A, Gibson M, Hunt SC, et al. Effect of Roux-en-Y gastric bypass surgery on the sex steroids and quality of life in obese men. J ClinEndocrinolMetab.2009; 94:1329 -1332.

[23]. Bastounis EA, Karayiannakis AJ, Syrigos K, et al. Sex hormone changes in morbidly obese patients after vertical banded gastroplasty. EurSurg Res. 1998;30:43-47.

[24]. Omana J, Tamler R, Strohmayer J, et al. Sex hormones in men undergoing bariatric surgery. J AmColl Surg. 2009;209:S22-S23.

[25]. Kobelt P, Wisser AS, Stengel A, Goebel M, Bannert N, Gourcerol G, et al. Peripheral obestatin has no effect on feeding behavior and brain Fos expression in rodents. Peptides. 2008;29:1018-27. [PMC free article] [PubMed ]

[26]. Chen CY, Ser KH, Chong K, Chen SC, Lee PC, Liao YD, Lee SD, Lee WJ; Differential influences of gastric bypass and sleeve gastrectomy on plasma nesfatin-1 and obestatin levels in patients with type 2 diabetes mellitus. 2013; Curr Pharm Des.19(32):58305[ PubMed ]

[27]. Haider DG, Schindler K, Prager G, Bohdjalian A, Luger A,Wolzt M \&Ludvik B. Serum retinol-binding protein-4 is reduced after weight loss in morbidly obese subjects. Journal of Clinical Endocrinology and Metabolism.2007; 92 1168-1171.

[28]. Nakahara T, Harada T, Yasuhara D, Shimada N, Amitani H, Sakoguchi T et al. Plasma obestatin concentrations are negatively correlated with body mass index, insulin resistance index, and plasma leptin concentrations in obesity and anorexia nervosa. Biological psychiatry. 2008; 64(3):252-5 
[29]. Lippl F, Erdmann J, Lichter N, Tholl S, Wagenpfei S, Adam O, Schusdziarra V. Relation of Plasma Obestatin Levels to BMI, Gender, Age and Insulin. HormMetab Re.2008;s; 40(11): 806-812.

[30]. Kang JG, Lee CB, Park H, Park CY. Relationship between Circulating Obestatin Levels and Obesity Index in Obese Patients.2009; Korean J Obes18(1):8-14.

[31]. Athyros VG, Tziomalos K, Karagiannis A, Mikhailidis DP. Cardiovascular benefits of bariatric surgery in morbidly obese patients. Obes Rev.2011; 12:515-24. [PubMed]. 